\title{
FAKTOR-FAKTOR YANG BERHUBUNGAN DENGAN DISMENOREA PADA SISWI SMP NEGERI 3 KARAWANG BARAT KABUPATEN KARAWANG TAHUN 2018
}

\author{
Factors related to dysmenorrhea \\ on Students in West Karawang 3 Middle School in 2018 \\ Wariyah $^{1}$, Herry Sugiri ${ }^{2}$, Imam Makhrus ${ }^{3}$ \\ Prodi Kebidanan Karawang Poltekkes Bandung \\ Wariyahmanda@gamil.com
}

\begin{abstract}
ABSTRAK
Latar Belakang : Menurut WHO angka dismenore di dunia sangat besar rata-rata lebih dari $50 \%$ perempuan di setiap Negara mengalami dismenore. Di Amerika Serikat diperkirakan hampir $90 \%$ wanita mengalami dismenore. Prevalensi wanita yang mengalami dismenore di Indonesia diperkirakan 55\%. Angka kejadian dismenore tipe primer di Indonesia sekitar 54,89\% yang menyebabkan mereka tidak mampu melakukan kegiatan apapun dan ini akan menurunkan kualitas hidup pada individu masing-masing.

Tujuan Penelitian : Penelitian ini bertujuan untuk mengetahui faktor-faktor apa saja yang berhubungan dengan dismenore pada siswi di SMP Negeri 3 Karawang Barat Tahun 2018.

Metode : Penelitian ini menggunakan metode analitik dengan menggunakan rancangan cross sectional. Populasi pada penelitian ini adalah siswi SMP Negeri 3 dengan jumlah sampel sebanyak 174 responden. Teknik dalam pengambilan sampel dengan stratified random sampling.

Hasil : Dari 83 responden yang di teliti di dapat angka kejadian dismenorhe sebanyak $55,4 \%$, sedangkan yang tidak dismenorhe sebanyak $44,6 \%$, usia menarche $\leq 9$ tahun sebanyak $1,2 \%$, dan usia menarche $>9$ tahun sebanyak $98,8 \%$, lama menstruasi $\leq 7$ hari sebanyak $42,2 \%$ dan $>7$ hari sebanyak 57,8 $\%$, riwayat keluarga ada yang dismenorhe sebanyak $61,4 \%$, dan yang tidak mempunyai riwayat dismenorhe sebanyak $38,6 \%$, yang melakukan olah raga, sebanyak $24,1 \%$ dan tidak olah raga sebanyak $79,9 \%$.
\end{abstract}

Simpulan: Ada hubungan antara riwayat keluarga dan olah raga dengan dismenorea di SMP Negeri 3 Karawang Barat tahun 2108

Kata Kunci : Dismenore, Faktor-faktor

\section{ABSTRACT}

Background: According to the WHO the number of dysmenorrhea in the world is very large, on average more than 50\% of women in each country experience dysmenorrhea. In the United States it is estimated that nearly $90 \%$ of women experience dysmenorrhea. The prevalence of women who experience dysmenorrhea in Indonesia is estimated at 55\%. The incidence of primary type 
dysmenorrhea in Indonesia is around $54.89 \%$ which causes them to be unable to carry out any activities and this will reduce the quality of life in each individual. The Aim : This study aims to determine what factors are associated with dysmenorrhea in female students in West Karawang 3 Middle School in 2018.

Method: This study used anlytic method using a cross sectional design. The population in this study were students of SMP Negeri 3 with a total sample of 174 respondents. Technique in sampling by stratified random sampling.

Results: Of the 83 respondents studied, the incidence of dysmenorrhea was $55.4 \%$, while the non-dysmenorrhea was $44.6 \%$, age of menarche $\leq 9$ years was $1.2 \%$, and age of menarche $>9$ years was $98.8 \%$, menstrual period $\leq 7$ days as much as $42.2 \%$ and $>7$ days as much as $57.8 \%$, family history of dysmenorrhea was $61.4 \%$, and those who did not have a dysmenorrheal history as much as $38.6 \%$, who did sports, $24.1 \%$ and $79.9 \%$ did not exercise.

Conclusion: There is a relationship between family history and exercise with dysmenorrhoea in West Karawang 3 Junior High School 3 in 2108

Keywords: Dysmenorrhea, Factors

\section{PENDAHULUAN}

Masa remaja merupakan masa transisi antara masa kanak-kanak ke masa dewasa atau suatu proses tumbuh kematangan yang mencakup kematangan mental, emosional, sosial dan fisik. Memasuki masa remaja yang diawali dengan kematangan seksual, maka remaja akan dihadapkan pada keadaan yang memerlukan penyesuaian untuk dapat menerima perubahan-perubahan yang terjadi. Kematangan seksual dan terjadinya perubahan bentuk tubuh sangat berpengaruh pada kehidupan kejiwaan remaja. Datangnya menarche dapat menimbulkan reaksi yang positif maupun negatif bagi remaja perempuan. Apabila mereka sudah disiapkan dan mendapat informasi tentang datangnya menstruasi maka mereka tidak akan mengalami kecemasan dan reaksi negatif, tetapi sebaliknya mereka yang tidak mendapat informasi maka akan merasakan kecemasan atau reaksi negatif. (Soetjiningsih, 2004).

Menurut Puji (2009), saat stress tubuh akan memproduksi hormon adrenalin, estrogen, progesteron serta prostaglandin yang berlebihan. Estrogen dapat menyebabkan peningkatan kontraksi uterus secara berlebihan. Terjadinya peningkatan estrogen secara berlebihan dapat menimbulkan rasa nyeri. Hormon adrenalin terjadi peningkatan sehingga menyebabkan otot tubuh menjadi tegang termasuk otot rahim dan dapat menimbulkan nyeri ketika menstruasi (Dismenorea).

Pada Umumnya wanita merasakan keluhan berupa nyeri atau kram perut menjelang menstruasi yang dapat berlangsung hingga 2-3 hari, dimulai dari sehari sebelum menstruasi. Nyeri perut saat menstruasi (dismenorea) yang dirasakan setiap wanita berbeda-beda, ada yang sedikit terganggu namun ada pula yang sangat terganggu sehingga tidak dapat menjalankan aktivitas sehari-hari dan membuatnya harus istirahat bahkan terpaksa absen dari sekolah/ pekerjaan. Dampak yang ditimbulkan dari dismenore adalah penurunan aktifitas sehari-hari 
sampai penggunaan terapi. Faktor resiko dismenore tidak hanya berkaitan dengan faktor fisiologis tetapi juga faktor psikologi termasuk kecemasan.

Menurut WHO angka dismenore di dunia sangat besar rata-rata lebih dari $50 \%$ perempuan di setiap Negara mengalami dismenore. Di Amerika Serikat diperkirakan hampir $90 \%$ wanita mengalami dismenore dan 10-15\% mengalami dismenore berat,yang menyebabkan mereka tidak mampu melakukan kegiatan apapun dan ini akan meurunkan kulitas hidup . Bahkan di Amerika diperkirakan perempuan kehilangan 1,7 juta hari kerja setiap bulan akibat dismenore. Dismenore menyebabkan $14 \%$ dari pasien remaja sering tidak hadir di sekolah dan tidak menjalani kegiatan sehari-hari. (French dan Masiroh, 2009).

Prevalensi wanita yang mengalami dismenore di Indonesia diperkirakan $55 \%$. Angka kejadian dismenore tipe primer di Indonesia sekitar 54,89\% yang menyebabkan mereka tidak mampu melakukan kegiatan apapun dan ini akan menurunkan kualitas hidup pada individu masing-masing (Proverawati, 2009). Penelitian yang dilakukan oleh Utami, dkk, terhadap siswi SMA Kabupaten Bone Sulawesi Selatan di dapat $87,1 \%$ remaja mengalami dismenore. Begitu juga penelitian yang dilakukan oleh Pundari dkk, pada mahasiswa di Universitas Jendral Soedirman di dapat $67,1 \%$ remaja dismenore. Penelitian yang dilakukan oleh Sophia dkk, pada siswi SMK Medan didapat kejadian dismenore sebanyak $81,30 \%$. Penelitian yang sama dilakukan oleh Kusuma EP kepada pelajar SMA/ sederajat di Semarang didapat angka kejadian dismenore sebanyak 68\%. Begitu juga hasil dari penelitian Kusumawati di SMAN 5 Pekan Baru didapat kejadian dismenore sebanyak 87\%. Dismenore salah satu masalah ginekologi yang paling sering terjadi dan dapat mempengaruhi lebih dari $50 \%$ wanita yang menyebabkan ketidak mampuan untuk melakukan aktivitas harian selama 1 sampai 3 hari setiap bulannya. Ketidak hadiran remaja di Sekolah adalah salah satu akibat dari dismenore primer mencapai kurang lebih 25\% (Reede, 2011).

Prevalensi dismenore cukup tinggi pada remaja. Dampak yang ditimbulkan dari dismenore adalah penurunan aktifitas sehari-hari sampai penggunaana terapi. resiko dari dismenore tidak hanya berkitan dengan faktor fisiologis tetapi juga faktor psikologi termasuk kecemasan. Gejala-gejala dismenore adalah kram dan sakit perut bagian bawah, sakit pada punggung belakang bagian bawah, mual, diare, muntah, kelelahan, pingsan, kelemahan dan sakit kepala. Wanita yang kelebihan berat badan, merokok dan yang sudah menstruasi sebelum umur 11 tahun beresiko lebih tinggi mengalami dismenore. (Calis, 2012).

Riwayat keluarga, lama menstruasi, usia menarche dan tidak melakukan aktivitas olah raga merupakan faktor resiko yang dapat meningkatkan terjadi dismenore. Hasil penelitian yang dilakukan oleh Handayani,(2014), bahwa ada hubungan yang bermakna riwayat keluarga dengan kejadian dismenore. Begitu juga dengan penelitian yang dilakukan oleh Utami dkk, (2013), bahwa riwayat keluarga berpengaruh terhadap kejadian dismenore.

Prevalensi kejadian dismenore di Indonesia cukup tinggi dan banyak terjadi pada usia remaja. Dari data diatas peneliti tertarik untuk melakukan penelitian tentang faktor-faktor yang berhubungan dengan dismenore pada siswi di SMP Negeri 3 Karawang Barat. 


\section{METODE PENELITIAN}

Penelitian ini menggunakan metode analitik dengan menggunakan rancangan cross sectional. Pendekatan ini dimaksudkan untuk melihat hubungan antara variabel dependen dengan variabel independen. Populasi pada penelitian ini adalah siswi SMP Negeri 3 Karawang Barat Kabupaten Karawang, dengan jumlah sampel sebanyak responden. Teknik dalam pengambilan sampel dengan stratified random sampling.

Pada penelitian ini menggunakan alat pengumpul data berupa kuesioner, Penelitian ini dilakukan dengan menggunakan data primer yaitu data yang dikumpulkan atau diperoleh berasal dari responden. Pengumpulan data dilakukan oleh peneliti dengan menggunakan kuesioner terstruktur, yaitu setiap item pertanyaan sudah disediakan pilihan jawaban atau responden mengisi jawaban singkat sesuai data yang dimilikinya.

\section{HASIL DAN PEMBAHASAN}

Tabel 1. Distribusi Frekuensi Kejadian Dismenorhe Di SMP Negeri 3 Karawang Barat Kabupaten Karawang Tahun 2018

\begin{tabular}{cccc}
\hline No. & Dismenorhe & $\mathrm{N}$ & $\%$ \\
\hline 1. & Ya & 46 & 55,4 \\
2. & Tidak & 37 & 44,6 \\
& Total & 83 & 100 \\
\hline
\end{tabular}

Dari tabel 1. diatas terlihat bahwa responden yang mengalami dismenorhe $46(55,4 \%)$, lebih banyak di bandingkan dengan responden yang tidak mengalami dismenorhe $37(44,6 \%)$.

Tabel 2. Distribusi Frekuensi Usia Menarche Di SMP Negeri 3 Karawang Barat Kabupaten Karawang Tahun 2018

\begin{tabular}{cccc}
\hline No. & Usia Menarche & $\mathrm{N}$ & $\%$ \\
\hline 1. & $\leq 9$ Tahun & 1 & 1,2 \\
2. & $>9$ Tahun & 82 & 98,8 \\
& Total & 83 & 100 \\
\hline
\end{tabular}

Dari tabel 2. terlihat bahwa responden usia menarche $\leq 9$ tahun sebanyak 1 responden $(1,2 \%)$, dan responden yang usia menarche $>9$ tahun yaitu sebanyak $82(98,8 \%)$.

Tabel 3. Distribusi Frekuensi Lama Menstruasi Di SMP Negeri 3 Karawang Barat Kabupaten Karawang Tahun 2018

\begin{tabular}{cccc}
\hline No. & Lamanya Menstruasi & N & $\%$ \\
\hline 1. & $\leq 7$ Hari & 35 & 42,2 \\
2. & $>7$ Hari & 48 & 57,8 \\
& Total & 83 & 100 \\
\hline
\end{tabular}


Dari tabel 3. terlihat bahwa responden yang lamanya menstruasi $\leq$ 7 hari sebanyak 35 responden (42,2\%), lebih sedikit bandingkan dengan responden yang lamanya menstruasi $>7$ hari yaitu sebanyak $48(57,8 \%)$.

Tabel 4. Distribusi Frekuensi Riwayat Keluarga Di SMP Negeri 3 Karawang Barat Kabupaten Karawang Tahun 2018

\begin{tabular}{cccc}
\hline No. & Riwayat Keluarga & $\mathrm{N}$ & $\%$ \\
\hline 1. & Ada & 51 & 61,4 \\
2. & Tidak ada & 32 & 38,6 \\
& Total & 83 & 100 \\
\hline
\end{tabular}

Dari tabel 4. Terlihat bahwa responden yang riwayat keluarga ada yang dismenorhe sebanyak 51 responden $(61,4 \%)$, lebih banyak di bandingkan dengan responden yang riwayat keluarga yang tidak dismenorhe yaitu sebanyak $32(38,6 \%)$.

Tabel 5. Distribusi Frekuensi Olah Raga Di SMP Negeri 3 Karawang Barat Kabupaten Karawang Tahun 2018

\begin{tabular}{cccc}
\hline No. & Olah Raga & $\mathrm{N}$ & $\%$ \\
\hline 1. & Ya & 20 & 24,1 \\
2. & Tidak & 63 & 75,9 \\
& Total & 83 & 100 \\
\hline
\end{tabular}

Dari tabel 5. terlihat bahwa responden yang melakukan olah raga sebanyak 20 responden $(24,1 \%)$, lebih sedikit di bandingkan dengan responden yang tidak melakukan olah raga yaitu sebanyak $63(75,9 \%)$.

Tabel 5. Hubungan Usia menarche dengan kejadian dismenorhe Di SMP Negeri 3 Karawang Barat Kabupaten Karawang Tahun 2018

\begin{tabular}{cccccccccc}
\hline & & \multicolumn{9}{c}{ Dismenorhe } & \multicolumn{3}{c}{ Jumlah } & & \\
\cline { 3 - 7 } No. & Usia & \multicolumn{2}{c}{ Ya } & \multicolumn{2}{c}{ Tidak } & $\mathrm{N}$ & $\%$ & $\mathrm{P}$ & OR \\
& Menarce & $\mathrm{n}$ & $\%$ & $\mathrm{~N}$ & $\%$ & & & & (CI 95\%) \\
\hline 1 & $\leq 9$ Tahun & 0 & $0 \%$ & 1 & 100 & 1 & 100 & & \\
2 & $>9$ Tahun & 46 & 56,1 & 36 & 43,9 & 82 & 100 & 0,44 & \\
& Total & 46 & 55,4 & 37 & 44,6 & 83 & 100 & & \\
\hline
\end{tabular}

Proporsi responden yang usia menarche $\leq 9$ Tahun yang mengalami dismenorche tidak ada, sedangkan responden yang usia menarche $>9$ tahun yang mengalami dismenorhe yaitu 46 responden (56,1\%). Dengan hasil uji statistik chi square didapat nilai $\mathrm{P}=0,446(\mathrm{P}>$ 0,05) Yang artinya Tidak ada hubungan yang bermakna antara usia menarche dengan kejadian dismenorche. 
Tabel 6. Hubungan Lama Menstruasi dengan kejadian dismenorhe Di SMP Negeri 3 Karawang Barat Kabupaten Karawang Tahun 2018

\begin{tabular}{cccccccccc}
\hline & & \multicolumn{9}{c}{ Dismenorhe } & \multicolumn{3}{c}{ Jumlah } & & \\
\cline { 3 - 7 } No. & Lama & \multicolumn{2}{c}{ Ya } & \multicolumn{2}{c}{ Tidak } & N & $\%$ & P & OR \\
& Menstruasi & $\mathrm{n}$ & $\%$ & $\mathrm{~N}$ & $\%$ & & & & $($ CI 95\%) \\
\hline 1 & $\leq 7$ Hari & 20 & 57,1 & 15 & 42,9 & 35 & 100 & & 1,128 \\
2 & >7 Hari & 26 & 54,2 & 22 & 45,8 & 48 & 100 & 0,82 & $(0,469-$ \\
& Total & 46 & 55,4 & 37 & 44,6 & 83 & 100 & & 2,714 \\
\hline
\end{tabular}

Proporsi responden yang lama menstruasi $\leq 7$ hari yang mengalami dismenorche sebanyak 20 responden $(57,1 \%)$ lebih sedikit dibandingkan dengan responden yang lama menstruasi $>7$ hari yaitu 26 responden (54,2\%). Dengan hasil uji statistik chi square didapat nilai $\mathrm{P}=0,82(\mathrm{P}>$ 0,05) Yang artinya Tidak ada hubungan yang bermakna antara lama menstruasi dengan kejadian dismenorhe.

Tabel 7. Hubungan Riwayat Keluarga dengan kejadian dismenorhe Di SMP Negeri 3 Karawang Barat Kabupaten Karawang Tahun 2018

\begin{tabular}{|c|c|c|c|c|c|c|c|c|c|}
\hline \multirow{3}{*}{ No. } & \multirow{3}{*}{$\begin{array}{l}\text { Riwayat } \\
\text { Keluarga }\end{array}$} & \multicolumn{4}{|c|}{ Dismenorhe } & \multicolumn{2}{|c|}{ Jumlah } & \multirow{3}{*}{$\mathrm{P}$} & \multirow{3}{*}{$\begin{array}{c}\text { OR } \\
\text { (CI 95\%) }\end{array}$} \\
\hline & & \multicolumn{2}{|c|}{$\mathrm{Ya}$} & \multicolumn{2}{|c|}{ Tidak } & \multirow[t]{2}{*}{$\mathrm{N}$} & \multirow[t]{2}{*}{$\%$} & & \\
\hline & & $\mathrm{n}$ & $\%$ & $\mathrm{~N}$ & $\%$ & & & & \\
\hline 1 & Ada & 40 & 78,4 & 11 & 21,6 & 51 & 100 & & 15.75 \\
\hline \multirow[t]{2}{*}{2} & Tidak ada & 6 & 18,8 & 26 & 81,2 & 32 & 100 & 0,00 & $(5,19-47,83)$ \\
\hline & Total & 46 & 55,4 & 37 & 44,6 & 83 & 100 & & \\
\hline
\end{tabular}

Proporsi responden yang mempunyai riwayat keluarga dismenorche sebanyak 40 responden $(78,4 \%)$ lebih banyak dibandingkan dengan responden yang tidak ada riwayat keluarga yaitu 6 responden $(18,8 \%)$. Dengan hasil uji statistik chi square didapat nilai $\mathrm{P}=0,00(\mathrm{P}<$ $0,05)$ Yang artinya ada hubungan yang bermakna antara riwayat keluarga dengan kejadian dismenorhe. Dengan nilai OR sebanyak 15,75. Artinya orang yang mempunyai riwayat keluarga berpeluang 15,75 kali mengalami dismenorhe dibanding dengan responden yang tidak mempunyai riwayat keluarga dismenorhe.

Tabel 8. Hubungan Olah Raga dengan kejadian dismenorhe Di SMP Negeri 3 Karawang Barat Kabupaten Karawang Tahun 2018

\begin{tabular}{cccccccccc}
\hline \multirow{2}{*}{ No. } & Olah Raga & \multicolumn{9}{c}{ Ya } & \multicolumn{4}{c}{ Tidak } & $\mathrm{N}$ & $\%$ & \multirow{2}{*}{$\mathrm{P}$} & \multirow{2}{*}{ OR } \\
\cline { 3 - 7 } & & $\mathrm{n}$ & $\%$ & $\mathrm{~N}$ & $\%$ & & & & (CI 95\%) \\
\hline 1 & Ya & 4 & 20,0 & 16 & 80 & 20 & 100 & & 0,12 \\
2 & Tidak & 42 & 66,7 & 21 & 33,3 & 63 & 100 & 0,00 & $(0,03-0,42)$ \\
& Total & 46 & 55,4 & 37 & 44,6 & 83 & 100 & & \\
\hline
\end{tabular}


Proporsi responden yang berolah raga yang mengalami dismenorche sebanyak 4 responden (20\%) lebih sedikit dibandingkan dengan responden yang tidak olah raga yaitu 16 responden $(80 \%)$. Dengan hasil uji statistik chi square didapat nilai $\mathrm{P}=0,00(\mathrm{P}>0,05)$ Yang artinya ada hubungan yang bermakna antara olah raga dengan kejadian dismenorhe. Artinya orang yang tidak berolah raga berpeluang 0,12 kali mengalami dismenorhe dibanding dengan responden yang berolah raga.

Dari hasil penelitian didapat bahwa dari 83 responden yang mengalami dismenorhe $55,4 \%$, lebih banyak di bandingkan dengan responden yang tidak mengalami dismenorhe 44,6\%. Terjadinya dismenorhe dikarenakan kontraksi rahim, di mana rahim mengalami kondisi mengencang dan melemas sehinga darah luruh dari rahim. Lapisan rahim melepas zat kimia khusus yang disebut prostaglandin. Ketika zat kimia ini dilepas dari dinding rahim, kekuatan kontraksi pun bertambah. Hal ini biasanya terjadi selama berhari-hari pada masa menstruasi. Kadar prostaglandin yang tinggi dapat menyebabkan nyeri perut dan kram yang parah. Hubungan usia menarche dengan dismenorhe tidak bisa di analisis karena ada salah satu sel yang nol (0)

Hasil penelitian tidak ada hubungan antara lama menstruasi dengan dismenorhe. Hasil penelitian ini tidak sejalan dengan penelitian yang dilakukan oleh Putri yang menyimpulkan bahwa terdapat hubungan antara lama menstruasi dengan dismenorhe pada siswi di SMPN 2 Kartasura. Perbedaan ini dikarenakan pada penelitian ini responden responden rata-rata menstruasinya 7 hari. Menurut Smeltzer\& Bare (2002), Menstruasi yang melebihi normal (> 7 hari) menstruasi menimbulkan adanya kontraksi uterus, terjadi lebih lama mengakibatkan uterus lebih sering berkontraksi dan semakin banyak prostaglandin yang dikeluarkan. Produksi prostaglandin yang berlebihan menimbulkan rasa nyeri, sedangkan kontraksi uterus yang terus-menerus menyebabkan suplai darah ke uterus terhenti dan terjadi dismenore.

Hasil penelitian ini menunjukkan ada hubungan yang bermakna anatara riwayat keluarga dengan dismenorhe. Hasil penelitian ini sejalan dengan hasil penelitian yang dilakukan oleh Putri, yang menyimpulkan terdapat hubungan yang bermakna antara riwayat keluarga dengan kejadian dismenorhe. Riwayat penyakit dalam keluarga dapat mengidentifikasi sesorang dengan resiko lebih tinggi untuk mengalami suatu penyakit. Riwayat keluarga juga merupakan faktor resiko untuk terjadinya dismenorhe, hal ini disebabkan karena secara anatomi dan fisiologi seseorang pada umumnya sama dengan keturunannya atau orang tuanya.

Hasil penelitian ini menunjukkan bahwa ada hubungan yang bermakna antara olah raga dengan kejadian dismenorhe. Hasil penelitian ini tidak sejalan dengan penelitian yang dilakukan oleh Pundati,dkk, menyimpulkan tidak ada hubungan kebiasaan olah raga dengan kejadian dismenorhe. Hasil ini penelitian berhubungan antara olah raga dengan dismenorhe dikarenakan olah raga merupakan salah satu teknik relaksasi untuk mengurangi rasa nyeri. Olah raga juga dapat menstimulasi pelepasan beta endorfine yaitu hormon yang bekerja sebagai analgesik nyeri non spesifik, yang dapat menurunkan derajat nyeri dismenorhe pada siklus menstruasi. 


\section{SIMPULAN DAN SARAN}

\section{Simpulan}

Dari 83 responden yang di teliti di dapat kejadian dismenorhe pada siswi SMPN 3 Karawang Barat sebanyak 55,4\%, sedangkan yang tidak dismenorhe sebanyak 44,6\%. Usia menarche $\leq 9$ tahun sebanyak $1,2 \%$, dan usia menarche $>9$ tahun sebanyak $98,8 \%$, lama menstruasi $\leq 7$ hari sebanyak $42,2 \%$ dan $>7$ hari sebanyak 57,8 \%, riwayat keluarga ada yang dismenorhe sebanyak $61,4 \%$, dan yang tidak mempunyai riwayat dismenorhe sebanyak $38,6 \%$, yang melakukan olah raga, sebanyak $24,1 \%$ dan tidak olah raga sebanyak 79,9\%. Dari 4 variabel independen yang mempunyai hubungan bermakna ada 2 variabel yaitu Riwayat keluarga nilai $(\mathrm{P}=0,00)$ dan olah raga dengan nilai $(\mathrm{P}=0,00)$, sedangkan 2 variabel tidak mempunyai hubungan bermakna yaitu variabel usia menache nilai $(\mathrm{P}=0,44)$, dan lama menstruasi nilai $(\mathrm{P}=0,82)$.

\section{Saran}

Diharapkan institusi kesehatan khususnya Puskesmas memberikan penyuluhan kepada remaja/siswi mengenai tanda dan gejala, serta penyebab dismenore. Dan sebaiknya para siswi harus mencari tahu tentang faktor resiko terjadinya dismenore, sehingga mereka yang memiliki faktor resiko mengalami dismenore dapat melakukan pencegahan dengan melakukan olah raga secara rutin.

\section{DAFTAR PUSTAKA}

Abdollahifard, S., Koshkaki, A. R. and Moazamiyanfar, R. (2014) 'The Effects of Vitamin B1 on Ameliorating the Premenstrual Syndrome Symptoms', 6(6), pp. 144-153. doi: 10.5539/gjhs.v6n6p144.

Bahri Annisa A.,Afriwardi, Yusrawati (2013), Hubungan antara kebiasaan olah raga dengan mahasiswa Pre- Klinik Progrm Studi Pendidikan Dokter Fakulata kedokteran Universitan Andlas Tahun ajaran 2012- 2013, Journal Fakultas Kedokteran

Bobak,2004, Buku Ajar Keperawatan Maternitas, Jakarta, EGC

Cahyaningtias Leilina Putri(2008), Pengaruh Olah raga terhadap derajat nyeri dismenorea pada wanita belum menikah, Journal Fakulatas kedokteran

Chocano-bedoya, P. O., Manson, J. E., Hankinson, S. E., Willett, W. C., Johnson, S. R., Chasan-taber, L., Ronnenberg, A. G., Bigelow, C. and Bertonejohnson, E. R. (2011) 'Dietary B vitamin intake and incident premenstrual syndrome 1-3', pp. 1080-1086. doi: 10.3945/ajcn.110.009530.1080.

Devi, M. (2009) 'Hubungan kebiasaan makan dengan kejadian sindrom pramenstruasi pada remaja putri', 32(2).

Handayani, Rahayu, 2014, Faktor-faktor yang berhubungan dengan nyeri menstruasi (dismenore) pada remaja putri di SMA N I Kabupaten Bone, Journal Kesehatan. 
Hoyer, J., Burmann, I., Kieseler, M., Vollrath, F., Hellrung, L., Arelin, K., Roggenhofer, E., Villringer, A. and Sacher, J. (2013) 'Menstrual Cycle Phase Modulates Emotional Conflict Processing in Women with and without Premenstrual Syndrome ( PMS ) - A Pilot Study', 8(4). doi: 10.1371/journal.pone.0059780.

Kusuma EP, 2015, Faktor-Faktor yang berhubungan dengan kejadian dismenore Primer pada pelajar di SMA/sederajat di Kecamatan Tambilin Semarang, Journak kesehatan.

Kusumayanti E, Faktor-faktor yang berhubungan dengan kejadian Dismenore di SMAN 5 Pekan Baru,Journal kesehatan.

Magdy Hassan Balaha1\&, Mostafa Abd El Monem Amr2, Mohammed Saleh Al Moghannum3, N. S. A. M. 1 (2010) 'Research article', The phenomenology of premenstrual syndrome in female medical students: a cross sectional stud, 8688, pp. 1-14.

Pundari,Sistiarini,Haryadi, 2016, Faktor-faktor yyang berhubungan dengan kejadian dismenore pada mahasiswi semester III Universitas Jendral Soedirman Purwekerto, Journal kesehatan masyarakat.

Reihane firoozi MSc 1 Mousa kafi Ph.D2 Iraj salehi Ph.D3 Maryam shirmohammadi (2012) 'The Relationship between Severity of Premenstrual Syndrome and Psychiatric Symptoms', pp. 36-40.

Sophia,Melda, Jumadi, Faktor-faktor yang berhubungan dengan dismenore Pada siswi SMK Negeri 10 Medan Tahun 2013,Journal

Tadakawa, M., Takeda, T., Monma, Y., Koga, S. and Yaegashi, N. (2016) 'The prevalence and risk factors of school absenteeism due to premenstrual disorders in Japanese high school students - a school-based crosssectional study', BioPsychoSocial Medicine. BioPsychoSocial Medicine, pp. 1-7. doi: 10.1186/s13030-016-0067-3.

Tolossa, F. W. and Bekele, M. L. (2014) 'Prevalence, impacts and medical managements of premenstrual syndrome among female students : crosssectional study in college of health sciences, Mekelle University, Mekelle ', BMC Women's Health. BMC Women's Health, 14(1), pp. 1-9. doi: 10.1186/1472-6874-14-52.

Manuaba,1998, Ilmu Kebidanan, Penyakit Kandungan dan Keluarga berencana Untuk Pendidikan Bidan, Jakarta,EGC.

Manuaba,1999, Memahami Kesehatan Reproduksi Waniata,Jakarta, Arcan

Nashruna, I., Wulandari, R., Belakang, L. and Pendahuluan, A. (2012) 'Hubungan aktivitas olah raga dan obesitas dengan kejadian sindrom pramenstruasi di desa pucang miliran tulung klaten', 9(1), pp. 65-75.

Notoatmojo,S,2005 Metodologi Penelitian Kesehatan, Jakarta, Rineka Cipta

Nurlela (2008) 'Hubungan olah raga dengan kejadian syndrome Premenstrum', Journal lти keperawatan, 3, pp. 1-5.

Utami, Ansar, Sidik, Faktor-faktor yang berhubungan dengan kejadian dismenore pada remaja putri Bone, Journal Kesehatan.

Pradhipta Rian Arifa (2011), Pengaruh therapi musik terhadap nyeri haid (dismenore) pada remaja putri kelas II di SMA Karangnongko Klaten,Journal Ilmu Keperawatan, 
Jurnal Kebidanan Indonesia. Vol 10 No 1. Januari 2019 (39-48)

Prawirohardjo, S,2005, Ilmu Kandungan, Jakarta, Yayasan Bina Pustaka Sarwono Prawirohardjo.

Widayanti S.D, Murdayanti S, Susmini, Pengaruh Aktivitas olah raga senam Body language Terhadap Penurunan Intensitas Nyeri Dismenorea Primer Pada Remaja Putri SMAN 2 Teluk Keramat Kabupaten Sambas Kalimantan Barat,Journal Ilmu Keperawatan,Volume 2 Nomor 1, 2017. 